\title{
Keratins: Biomarkers and Modulators of Apoptotic and Necrotic Cell Death in the Liver
}

\author{
Nam-On Ku, ${ }^{1}$ Pavel Strnad, ${ }^{2}$ Heike Bantel, ${ }^{3}$ and M. Bishr Omary ${ }^{4-6}$
}

\begin{abstract}
Keratins, formerly known as cytokeratins, are the major epithelial-specific subgroup of intermediate filament proteins. Adult hepatocytes express keratin polypeptides 8 and 18 (K8/K18), whereas cholangiocytes express K8/K18 and keratins 7 and 19 (K7/ K19). Keratins function primarily to protect hepatocytes from apoptosis and necrosis, which was revealed using several genetic mouse models. This cytoprotective function was further clarified by the identification of natural human keratin variants that are normally silent, but become pathogenic by predisposing their carriers to apoptosis during acute or chronic liver injury mediated by toxins, virus infection, or metabolic stress. During apoptosis, caspases cleave K18 and K19 at conserved aspartates (human K18/K19: ${ }^{235}$ Val-Glu-Val-Asp ${ }^{\downarrow}$ ) and K18 at a unique aspartate (human K18: ${ }^{394}$ Asp-Ala-Leu-Asp ${ }^{\downarrow}$ ), with the latter exposed epitope becoming recognized by the M30 antibody in blood and tissues. Additional K18-containing protein backbone epitopes are detected using the M6 and M5 (termed M65) antibodies. Intact K18 and its associated fragments, which are released into blood during apoptosis and necrosis in various diseases, have been analyzed by enzyme-linked immunosorbent assay using the M30/M65 antibodies or their signal ratios. Furthermore, M30/M65 levels have been used as diagnostic and prognostic biomarkers in acute and chronic liver diseases, including nonalcoholic steatohepatitis and acute liver failure. Other keratin biomarkers include K8/K18/K19-related tissue polypeptide antigen, K18-related tissue polypeptide-specific antigen, and K19related CYFRA-21-1, which have been evaluated mostly in patients with epithelial tumors. Conclusion: Keratins and their fragments are released into blood during liver and other epithelial tissue injury. The epithelial specificity of K18/K19, epitope unmasking upon caspase digestion, keratin abundance, and relative keratin stability render them useful biomarkers for hepatocyte and cholangiocyte apoptosis and necrosis. However, the precise biochemical nature and release mechanism of circulating keratins remain unknown. (HePATOLOGY 2016;64:966-976)
\end{abstract}

he cytoskeleton of most mammalian cells includes three major filament networks: microfilaments, microtubules, and intermediate filaments $(\mathrm{IFs}){ }^{(1)} \mathrm{IFs}$ consist of a large family of tissuespecific proteins that include the cytoplasmic keratins as the largest subgroup, vimentin, neurofilaments, and lamins, among others. ${ }^{(2-4)}$ Keratin (K) IFs are selectively expressed in epithelial cells and serve as cell-specific markers. ${ }^{(5)}$ Whereas early publications referred to keratins as cytokeratins, ${ }^{(6)}$ and the latter term remains used by some, keratins is now the recommended name based on an internationally accepted consensus ${ }^{(7)}$ and this is

Abbreviations: ALF, acute liver failure; ALT, alanine aminotransferase; AUC, area under the curve; CYFRA 21-1, CYtokeratin FRAgments with MAbs BM19.21 and KS19.1; ELISA, enzyme-linked immunosorbent assay; GVHD, graft-versus-host disease; HBV, hepatitis B virus; HCC, hepatocellular carcinoma; HCV, hepatitis $C$ virus; IFs, intermediate filaments; $K$, keratin; KCC, King's College Criteria; LT, liver transplantation; MELD, Model for end-stage liver disease; NAFLD, nonalcoholic fatty liver disease; NAS, NAFLD Activity Score; NASH, nonalcoholic steatohepatitis; PBC, primary biliary cirrhosis; PTMs, posttranslational modifications; TNF- $\alpha$, tumor necrosis factor alpha; TPA, tissue polypeptide antigen; TPS, tissue polypeptide-specific antigen; WT, wild type.

Received October 7, 2015; accepted February 3, 2016.

Additional Supporting Information may be found at onlinelibrary.wiley.com/doi/10.1002/hep.28493/suppinfo.

The authors' work is supported by the Korean Ministry of Education, Science and Technology (grant no.: 2013R1A1A2006303; to N.-O.K.); the German Research Foundation grants STR 1095/2-1, 1095/4-1, 1095/5-1, and SFB TRR57 and funding of the Interdisciplinary Center for Clinical Research (IZKF) in Aachen (to P.S.); the German Research Foundation grants BA-2092/9-1 and SFB TRR77 (to H.B.); and National Institutes of Health grants DK47918 and DK52951 and the Department of Veterans Affairs (to M.B.O.).

Copyright $(0) 2016$ by the American Association for the Study of Liver Diseases.

View this article online at wileyonlinelibrary.com.

DOI 10.1002/hep.28493

Potential conflict of interest: Nothing to report. 
the term we use and recommend. All IFs share a common protein organization backbone that consists of a central $\alpha$-helical "rod" domain that is flanked with non$\alpha$-helical "head" and "tail" domains. ${ }^{\left({ }^{(8)}\right.}$ Keratins consist of type I (K9-K28, K31-K40) and II (K1-K8, K71$\mathrm{K} 86) \mathrm{IFs}^{(2,7)}$ that form obligate noncovalent heteropolymeric type I/II complexes that polymerize to form characteristic 10-nm-wide filamentous arrays. A unique feature of the different type I/II keratin pairs is their epithelial cell-specific expression. For example, K5/K14 and K1/K10 are found in basal and suprabasal keratinocytes, respectively, whereas combinations of the type II K7 or K8 and type I K18/K19/K20/K23 are expressed in simple-type (single-layered) epithelial cells as found in digestive-organ epithelia. ${ }^{(9)} \mathrm{K} 8$ and $\mathrm{K} 18$ are the only keratins found in adult hepatocytes, whereas cholangiocytes express K7/K19 with K8/K18. ${ }^{(9)}$

Apoptosis and necrosis are the typical modes of cell death in liver diseases, including viral, fatty, cholestatic, and alcohol-related disorders. ${ }^{(10)}$ The apoptotic pathway is triggered by binding of extracellular death ligands, such as Fas ligand or tumor necrosis factor alpha (TNF$\alpha$ ), to death receptors (Fas and TNF-R1/R2 receptors, respectively) and is culminated by caspase activation and degradation of numerous cellular proteins. ${ }^{(11,12)}$ Indeed, mice treated with a Fas agonist antibody develop acute liver failure and may die depending on the experimental conditions. ${ }^{(13)}$ Among the many substrates that are cleaved during apoptosis are the cytoskeletal components actin, ${ }^{(14)}$ tubulin, ${ }^{(15,16)}$ and several IFs, including lamins ${ }^{(17)}$ and keratins. ${ }^{(18,19)}$ Notably, only type I, but not type II, keratins are caspase substrates. ${ }^{(19)}$

Keratins in the liver serve several important mechanical and nonmechanical cellular and subcellu- lar functions. The K8/K18 mechanical function, ${ }^{(20,21)}$ similar to other IFs, ${ }^{(5)}$ endows hepatocytes with stability that protects them from necrosis. ${ }^{(9)}$ This mechanical function, which allows cells and tissues to cope with deformations, sets IFs apart from microfilaments and microtubules. ${ }^{(22)}$ Nonmechanical functions of keratins include facilitation of protein targeting to subcellular compartments, ${ }^{(9)}$ modulation of protein synthesis, ${ }^{(23)}$ organelle positioning, ${ }^{(24)}$ and protection from apoptosis and necrosis. ${ }^{(23-25)}$ This review focuses on hepatobiliary aspects related to: (1) biochemical events that lead to keratin proteolysis by caspases during apoptosis; (2) keratin functions related to cell injury and death; and (3) the utility and caveats of measuring keratin fragments as biomarkers of liver injury.

\section{Keratins 18 and 19 Digestion by Caspases as a Post-Translational Modification}

Keratins undergo several covalent post-translational modifications (PTMs), including phosphorylation, glycosylation, ubiquitination, sumoylation, transamidation, and acetylation. ${ }^{(26)}$ These modifications regulate keratin filament organization, subcellular localization, solubility, turnover, interaction with binding proteins, and, consequently, keratin function. The best understood modification is keratin phosphorylation, which is highly relevant because significant increases in keratin

\section{ARTICLE INFORMATION:}

From the ${ }^{1}$ Department of Integrated OMICS for Biomedical Science, Graduate School, Yonsei University, Seoul, Korea; ${ }^{2}$ Department of Internal Medicine III and IZKF, University Hospital Aachen, Aachen, Germany; ${ }^{3}$ Department of Gastroenterology, Hepatology and Endocrinology, Hannover Medical School, Hannover, Germany; ${ }^{4}$ Department of Molecular \& Integrative Physiology, University of Michigan Medical School, Ann Arbor, MI; ${ }^{5}$ Department of Medicine, University of Michigan Medical School, Ann Arbor, MI; and ${ }^{6}$ VA Ann Arbor Health Care System, Ann Arbor, MI

\section{ADDRESS CORRESPONDENCE AND REPRINT REQUESTS TO:}

Nam-On Ku, Ph.D.

Department of Integrated OMICS for Biomedical Science,

Graduate School, Yonsei University

Seoul 120-749,

Korea

Tel: + 82-2-2123-2697

E-mail: namonku@yonsei.ac.kr

or
Pavel Strnad, M.D.

Department of Internal Medicine III and IZKF,

University Hospital Aachen

Pauwelsstraße 30, 52074 Aachen

Germany

Tel: +492418035324

E-mail: pstrnad@ukaachen.de 
TABLE 1. Conserved Caspase Recognition Sites Across Species

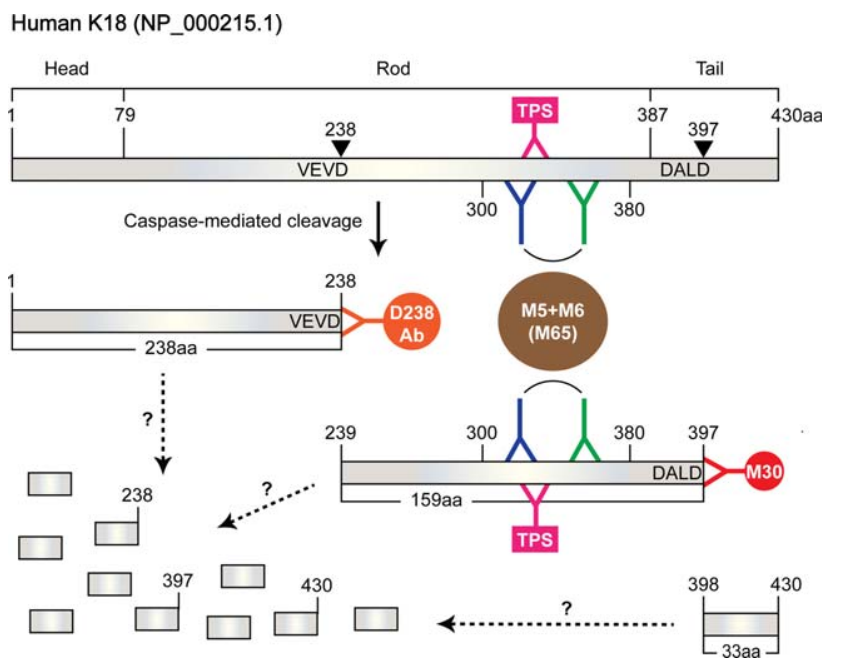

FIG. 1. K18 cleavage during apoptosis. Human K18 has two caspase cleavage sites. VEVD 238 is highly conserved among other IFs, whereas the $\mathrm{DALD}^{397}$ is unique to K18. The cleavage occurs sequentially at $\mathrm{DALD}^{397}$ and then VEVD ${ }^{238}$. The D238 antibody specifically recognizes the neo-epitope $\mathrm{VEVD}^{238}$, whereas the M30 antibody recognizes DALD $^{397}$ digestion. ${ }^{(30,33)}$ M65 are two monoclonal antibodies, M6 and M5, that recognize K18 epitopes between amino acids $300-380^{(88)}$ (PEVIVA AB, Bromma, Sweden). TPS antibody recognizes a K18 epitope within amino acids $322-340 .{ }^{(87,88)}$ The caspase-cleaved K18 fragments are finally further degraded by presumed proteinases (?). Abbreviations: Ab, antibody; aa, amino acid.

phosphorylation occur in the context of cell injury attributed to activation of stress and other kinases. ${ }^{(26,27)}$ Keratin phosphorylation is among the earliest biochemical events that take place after an apoptotic stimulus, and mice that express phospho-mutant human K18 Ser53Ala ${ }^{(28)}$ or K8 Ser74Ala ${ }^{(29)}$ are predisposed to Fas-mediated liver injury.

Another form of a noncovalent keratin PTM is proteolysis of type I keratins, including K18 and K19, by caspases during apoptosis. ${ }^{(9)} \mathrm{K} 18$ has two caspase recognition sites (Fig. 1): $\operatorname{VEVD}^{238}$, which is conserved across species and most IFs, and a unique DALD 397 site that is present only in K18 and not other keratins/ $\operatorname{IFs}^{(18,19,30)}$ (Table 1). The caspase-mediated K18 cleavage occurs first at the aspartate of DALD ${ }^{397 \downarrow}$ and then at $\mathrm{VEVD}^{238 \downarrow}{ }^{2},{ }^{30,31)}$ with the first cleavage event occuring early before detection of Annexin $V$ staining and DNA fragmentation. ${ }^{(30,32)}$ Notably, the unmasked neoepitopes at K18 $\operatorname{VEVD}^{238}$ or $\mathrm{DALD}^{397}$ are detected by epitope-specific antibodies: a mouse monoclonal M30 antibody recognizes the fragment ending with $\mathrm{DALD}^{397}$, whereas a rabbit polyclonal

\begin{tabular}{lccc} 
Species & K18 VEVD & K18 DALD & K19 VEVD \\
\hline Human & SGLTVEVDAPK & NLGDALDSSN & GGQVSVEVDSAPG \\
Cow & SGLTVELDAPK & SLGDALDSSN & GGQVSVEVDSAPG \\
Mouse & SGLTVEVDAPK & SLNDALDSSN & GGQVSVEVDSTPG \\
Opossum & SGLTVEVDSPK & NLVHALDGSS & GGQVSVEVDSAPG \\
Chicken & SGLTVEVDSPK & NLVHALDGSS & ASQVSVEVDSAPG \\
Frog & NNVKVEVEGPK & NLMDLNQQIS & GGQISVEVDAAPT \\
Zebrafish & SQSGVQVDVDA & KLQDALEEQ & Unknown
\end{tabular}

antibody recognizes the fragment ending with VEVD $\left.^{238} \cdot 33,34\right)$ Such antibodies provide powerful tools to assess epithelial cell apoptosis by detecting and quantifying apoptotic and nonapoptotic K18 (and K19) species in serum/plasma. The M30 and M65 enzyme-linked immunosorbent assays (ELISAs) have been used in more than 100 liver- and non-liverrelated studies to assess disease activity and the contribution of apoptosis or total cell death to disease pathogenesis (Supporting Table S1).

Caspase-mediated cleavage of cytoskeletal components, including K18/K19, is presumed to allow reorganization of the filament network, thereby permitting retraction of the affected cells and membrane blebbing that are observed at early stages of apoptosis. ${ }^{(11)}$ Although it is known that the three major cytoskeletal elements are caspase substrates, ${ }^{(14,15)}$ including cytolinker proteins such as plectin, ${ }^{(35)}$ the orchestration and sequence of cytoskeleton alterations are poorly understood.

The physiological significance of caspase-mediated K18 cleavage appears to be related to allowing keratin filaments to reorganize. This is supported by findings in transgenic mice that overexpress a caspase-resistant K18 mutant (K18-DE) with Asp (D)-to-Glu (E) mutation at the two caspase cut sites (D238/D397). Keratin filaments in livers and isolated hepatocytes from K18-DE mice were not able to reorganize and disassemble upon Fas stimulation in vivo and $e x$ vivo. ${ }^{(34)}$ These mice also developed more severe Fastriggered liver damage, as compared to mice that overexpressed wild-type (WT) K18. The enhanced K18 DE liver injury is attributed to shunting of cell death from apoptosis to necrosis in association with keratin hypophosphorylation ${ }^{(34)}$ at a serine that normally protects from apoptosis when phosphorylated. ${ }^{(29)}$ Hence, K18 caspase cleavage during apoptosis allows for the progression of keratin reorganization during apoptosis (Fig. 2). The mechanism of the shunting of cell death 


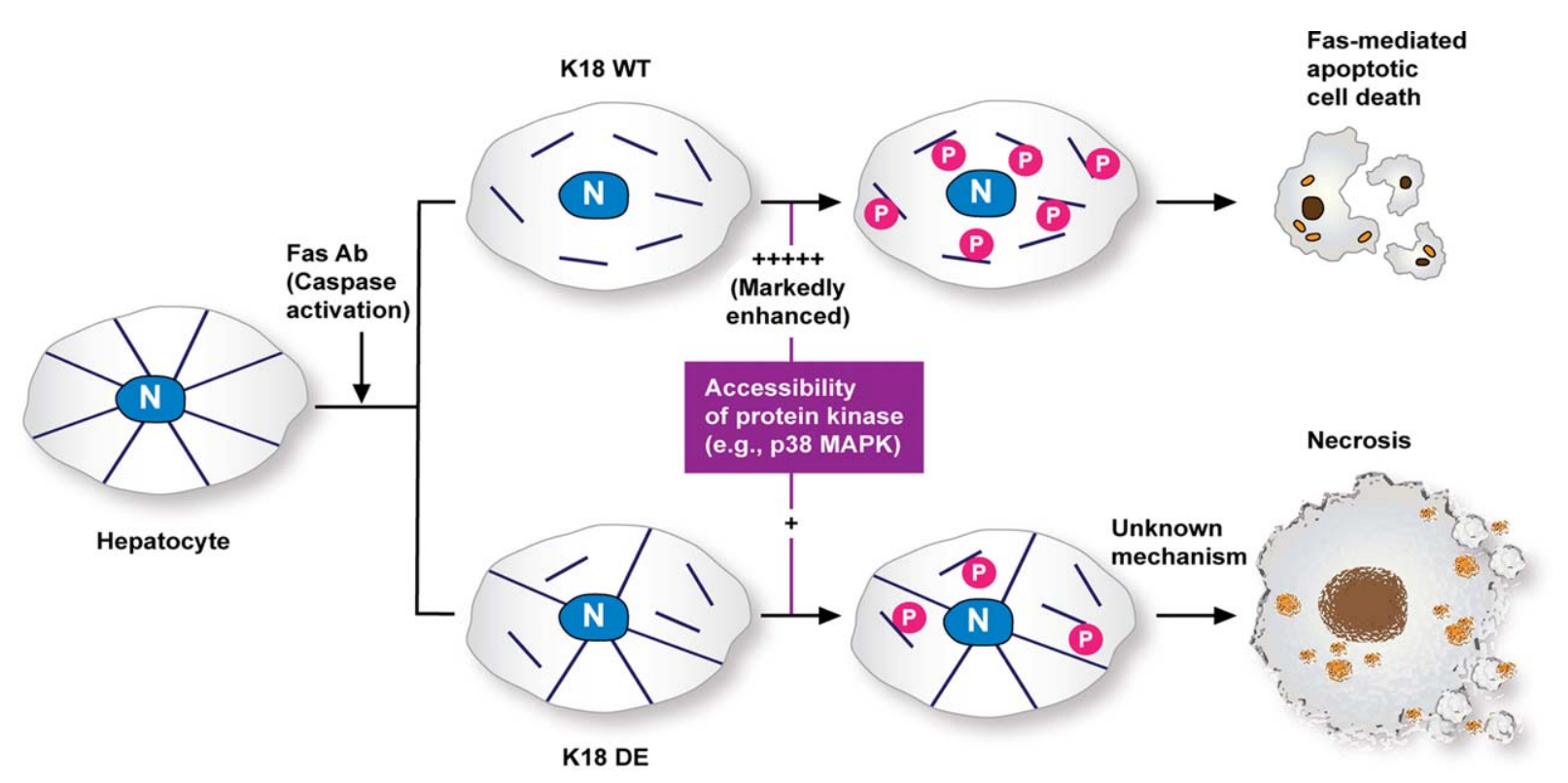

FIG. 2. Effect of inhibiting K18 fragmentation on keratin filament organization and Fas-mediated liver damage. Mutation of the two K18 caspase cleavage sites (K18 DE) results in several consequences, including keratin hypophosphorylation, inability of the keratin filaments to reorganize, and shunting toward cell necrosis rather than apoptosis. Abbreviations: Ab, antibody; MAPK, mitogenactivated protein kinase.

toward necrosis when K18 cleavage is blocked remains to be investigated.

\section{Keratin Variants Predispose to Cell Death and Liver Disease Progression}

The essential cytoprotective function of keratins is supported by more than 60 different disorders that are linked to the presence of inherited keratin variants (www.interfil.org). ${ }^{(36-38)}$ For example, KRT8 and $K R T 18$ variants associate with progression of several chronic liver diseases, including hepatitis $\mathrm{C}$, primary biliary cirrhosis (PBC), and what was initially associated with cryptogenic cirrhosis that is likely primarily attributed to nonalcoholic fatty liver disease (NAFLD). ${ }^{(39,40)}$ In addition, K19 G17S substitution associates with disease progression in patients with PBC. ${ }^{(41)}$ Further studies are needed to evaluate the biological importance of this and other potential K19 variants. K8/K18 variants also associate significantly with acute liver failure (ALF) progression and the need for liver transplantation (LT) or patient death. ${ }^{(42)}$ In addition, K18 (D90H) and K8 (K393R) mutation at residues that disrupt keratin cytoskeletal organization were found in 2 patients who died from isoniazid and ezetimibe/simvastatin hepatoxicity, respectively. ${ }^{(38)}$

The mechanism by which human keratin variants predispose to liver injury appears to be primarily nonmechanical. For example, some variants impair keratin phosphorylation at adjacent residues, which renders K18 more susceptible to digestion by caspases. The mutation-triggered predisposition to apoptosis is pathway dependent, in that two different K18 mutations in transgenic mice predispose to Fas, but not TNFmediated apoptosis. ${ }^{(34,43)}$ As compared with epidermal keratin mutations, which as a group cause disease and are highly penetrant, $\mathrm{K} 8 / \mathrm{K} 18$ variants predispose to (liver) disease rather than cause disease per se, are more common and display race/ethnic associations. ${ }^{(9,38,42)}$ For example, K8 Y54H and G434S are the most common amino-acid-altering variants in individuals of African descent and are found in $\sim 3.6 \%$ and $\sim 8 \%$ of liver-healthy groups, respectively. ${ }^{(38,44)}$ In contrast, K8 G62C and $\mathrm{R} 341 \mathrm{H}$ are the most abundant substitutions found in Caucasians (variant frequencies 1\%-2\% and $\sim 6 \%$, respectively). ${ }^{(38)}$ The K8/K18 common variants are typically located in less-conserved keratin regions (head and tail, Fig. 1), whereas mutations in the most-conserved K8/K18 subdomains are rare 
(variant frequencies $<0.1 \%$ ). ${ }^{(38)}$ An extensive body of works indicate that keratin variants predispose their carriers to both apoptotic and nonapoptotic cell death depending on the pathological challenge and location of the mutation. . $^{(9,23,25,29,34,38)}$

\section{Clinical Utility of K18 as a Liver Disease Biomarker}

Liver biopsy represents the gold standard for diagnosis and evaluation of the activity or progression of liver diseases, but it bears important risks. Given that a liver biopsy specimen represents $\sim 1$ in 50,000 of the total liver mass, sampling errors might limit interpretations. ${ }^{(45)}$ Intra-/interobserver variability may also contribute to misinterpretations. ${ }^{(46)}$ Therefore, much attention has focused on the identification of noninvasive biomarkers that can detect liver disease activity or progression. Increased apoptosis and/or necrosis play a role in the pathogenesis of various liver diseases and determine disease activity and progression. ${ }^{(10,47,48)}$ Thus, biomarkers of hepatocyte apoptosis or necrosis have been used to monitor acute and chronic liver diseases. During hepatocyte apoptosis, activated caspases cleave K18, which can be detected in serum or plasma by the M30 ELISA, ${ }^{(49)}$ whereas the M65 ELISA detects both caspase-cleaved and uncleaved (total) K18. ${ }^{(49,50)}$ Several mechanisms may contribute to K18 release to the extracellular space. As such, K18 fragments form cytoplasmic inclusion bodies and occur in apoptotic cell-surface blebs, ${ }^{(51)}$ and keratins can circulate in serum within extracellular vesicles. ${ }^{(52)}$ Further studies are needed to delineate the modes of keratin release from cells (e.g., within vesicles, apoptotic bodies, full length, apoptotic and nonapoptotic fragments). Findings from these studies will likely refine the currently used assays and enhance their utility.

Here, we summarize studies that have utilized keratins as potential biomarkers in acute and chronic liver disease. We focus on primary hepatobiliary diseases, although the M30/M65 ELISAs have been used in other glandular-tissue-type injury, such as gastrointestinal/liver graft-versus-host disease (GVHD). ${ }^{(53)}$

\section{Role of K18 Biomarkers in Acute Liver Diseases}

ALF is potentially life threatening, whereby the decision for LT should be made as early as possible. Therefore, noninvasive biomarkers are urgently needed. Notably, ALF patients have significantly higher circulating levels of caspase-cleaved (M30) and presumed total K18 (M65), as compared to healthy individuals. ${ }^{(50,54,55)}$ Whether apoptotic and/or necrotic cell death predominates in ALF and how their proportion influence the outcome remain largely unclear and likely depend on the etiology, severity, and duration of the ALF. ${ }^{(56)}$ Nevertheless, it was demonstrated that modification of the Model for End-Stage Liver Disease (MELD) score by substitution of bilirubin with total K18 significantly improved the prediction of ALF outcome at the day of hospital admission. ${ }^{(57)}$ Moreover, the U.S. ALF Study Group proposed an ALF index that combines clinical markers and M30 levels and thus allowed better prediction of ALF outcome as compared to the routinely used King's College Criteria (KCC) or MELD score. ${ }^{(58)}$ However, although serological detection of M65 or M30 levels allowed the prediction of ALF outcome in paracetamol intoxication, ${ }^{(59,60)}$ neither M30 nor M65 levels were superior to $\mathrm{KCC}$ in those patients. ${ }^{(61)}$ Thus, combination of these cell death biomarkers with other prognostic parameters of ALF might be required to improve the assessment of ALF outcome.

\section{Role of K18 Biomarkers in Chronic Liver Diseases}

\section{VIRAL HEPATITIS}

Chronic hepatitis $\mathrm{B}$ or $\mathrm{C}$ virus (HBV/HCV) infections are accompanied by variable degrees of hepatic inflammation and fibrosis. Apoptosis plays an important role in inflammatory liver damage and fibrosis progression and is associated with increased risk of cirrhosis and hepatocellular carcinoma (HCC). ${ }^{(62)}$ For example, caspase-mediated K18 cleavage correlated with inflammatory disease activity in livers from patients with chronic HCV infection. ${ }^{(4)}$ Similarly, patients with chronic $\mathrm{HBV}$ infection showed higher serum M30 levels compared to healthy controls. ${ }^{(63)}$ M30 serum levels correlated with histological disease activity in chronic HCV or HBV infection. ${ }^{(64,65)}$ Vice versa, M30 levels declined with successful antiviral treatment of chronic HCV or HBV infection. ${ }^{(66,67)}$ Elevated M30 levels could even be detected in sera from patients with chronic $\mathrm{HCV}$ or $\mathrm{HBV}$ infection and normal aminotransferase activity. ${ }^{(49,63,68)}$ In this respect, patients with $\mathrm{HBeAg-negative} \mathrm{chronic} \mathrm{HBV}$ infection and transiently normal aminotransferases had 
higher M30 serum levels compared to inactive carriers. ${ }^{63)}$ Interestingly, the majority of patients with chronic HCV infection and normal aminotransferase levels had histological evidence of progressive fibrosis, ${ }^{(49)}$ which is consistent with other studies showing elevated M30 levels in association with advanced fibrosis or cirrhosis (Supporting Table 1). ${ }^{(68,69)}$ Both apoptosis and necrosis have been proposed as responsible for development and progression of liver fibrosis. ${ }^{(62)}$ However, unlike the M30 ELISA, detection of total K18 by the M65 ELISA might allow the discrimination of lower fibrosis stages in chronic liver disease. ${ }^{(69)}$ Whether differential sensitivity in detection of lower fibrosis stages between the M30 and M65 assays reflects different cell death modes or whether different stability of the K18 forms might influence the sensitivity remains to be investigated.

\section{NAFLD}

NAFLD is one of the most common causes of chronic liver diseases, ranging from simple steatosis to nonalcoholic steatohepatitis (NASH) with the risk of developing liver cirrhosis and HCC. ${ }^{(70)}$ Notably, aminotransferase levels are within the normal range in nearly $80 \%$ of patients with fatty liver. ${ }^{(71)}$ However, NASH can be diagnosed in up to $59 \%$ of patients despite normal aminotransferases, ${ }^{(72,73)}$ and $>50 \%$ of patients with steatosis progress toward NASH and more than half of them develop fibrosis progression within 3 years. ${ }^{(74)}$ Therefore, novel biomarkers to detect NAFLD activity and monitor disease progression are needed. Because hepatocyte apoptosis plays a critical role in NAFLD-associated liver injury, and aminotransferases are not sensitive enough for the diagnosis of NASH, the M30 assay became an extensively evaluated marker for detecting NAFLD activity. ${ }^{(75)}$

Early studies showed that plasma M30 is higher in patients with NASH, compared to steatosis, and might allow discrimination between both entities. ${ }^{(76)}$ Subsequent studies (Supporting Table 1) confirmed an increase of caspase-cleaved K18 fragments in NASH patients compared to patients with simple steatosis. ${ }^{(69)}$ The diagnostic performance of K18 fragments in $\mathrm{NASH}$ detection was promising, with area under the curve (AUC) values ranging from 0.77 to $0.93 .{ }^{(77)}$ However, the diagnostic performance of caspasecleaved K18 for detection of NASH has been recently questioned, ${ }^{(78)}$ given that AUC values of 0.65 and of 0.68 were calculated for prediction of NASH or fibrosis, respectively, in NAFLD patients. ${ }^{(78)}$ Nevertheless, plasma/serum K18 fragment levels were significantly higher in NAFLD patients with moderate-to-severe fibrosis compared to those with no or mild fibrosis. ${ }^{(77,79)}$ Moreover, K18 fragments correlated significantly with the degree of steatosis, lobular inflammation, and ballooning ${ }^{(77,79-81)}$ and more accurately reflected histological NAFLD Activity Score $(\mathrm{NAS})^{(82)}$ compared to alanine aminotransferase (ALT) levels. ${ }^{(81)}$ In addition, changes in M30 levels closely paralleled NAS, ${ }^{(75,81)}$ which was not observed for aminotransferase levels. ${ }^{(81)}$ Another study confirmed a significantly stronger decrease of M30 levels in patients with histological improvement compared to those without changes in NAS, although reductions in M30 levels were not better than ALT levels for identification of patients with histological NAFLD improvement. ${ }^{(83)}$ Similarly, M30 levels declined significantly in parallel with aminotransferase levels in NAFLD patients after bariatric surgery. ${ }^{(77)}$

In contrast to M65, M30 was unable to predict $\mathrm{NASH}$ independently of ALT levels. ${ }^{(69)}$ In line with this observation, a composite model including both ALT and caspase-cleaved K18 revealed a higher accuracy for prediction of NAFLD activity compared to detection of caspase-cleaved K18 alone. ${ }^{(84)}$ Otherwise, a higher diagnostic performance of total K18, compared to caspase-cleaved K18 for prediction of NASH, could be demonstrated. ${ }^{(85,86)}$ Further studies are needed to explore whether total K18 levels might be superior for predicting and monitoring of NAFLD disease activity. In summary, the M30 and M65 ELISAs represent a reliable and sensitive method for noninvasive detection of liver disease activity and progression and have been extensively evaluated in NAFLD (Fig. 3). Furthermore, assessment of K18 fragments became part of prospective NAFLD studies ${ }^{(74,87)}$ and such data will help our understanding of the usefulness of K18-based biomarkers in this context.

\section{KERATIN FRAGMENTS IN LIVER CANCER AND NONMALIGNANT LIVER DISEASES}

Although M30/M65 currently represent the most widely used keratin-based serum markers, other tumor markers also rely on detection of keratin fragments. For example, tissue polypeptide antigen (TPA) recognizes K8, K18, and K19, whereas tissue polypeptidespecific antigen (TPS) and keratin fragments 21-1 (CYFRA 21-1) detect K18 and K19, respectively. ${ }^{(9,40)}$ Several commercial assays exist for these markers ${ }^{(88)}$ 


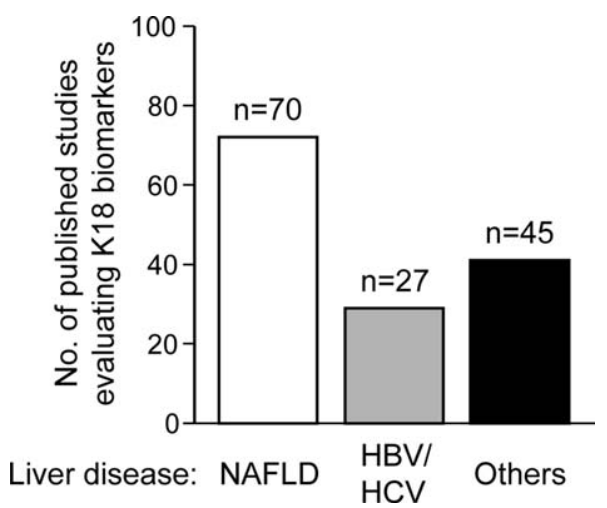

FIG. 3. Number of published original articles using K18 biomarkers (M30 or M65) in NAFLD ( $\mathrm{n}=70)$, HBV ( $=10)$, $\operatorname{HCV}(n=17)$ infections, and other liver diseases $(n=45)$.

(Fig. 4). The epitopes recognized by M65 and TPS are localized in the C-terminal portion of the rod domain, with TPS being restricted to K18 amino acids 322$340^{(89,90)}$ (Fig. 1). Although the diagnostic benefit of TPS, TPA, and CYFRA 21-1 have been evaluated in multiple human malignancies and showed prognostic value particularly in breast and lung cancers, these markers are not routinely used in the clinic because of their low sensitivity. ${ }^{(88)}$ CYFRA $21-1$ might have prognostic relevance in $\mathrm{HCC},{ }^{(91,92)}$ but further studies are needed to clarify its usefulness. Given the emerging negative prognostic value of K19 expression in $\mathrm{HCC}$, ${ }^{(93)}$ future studies should assess the ratio between serum K19 (CYFRA 21-1) and K18 levels (M65/ TPS). Finally, CYFRA 21-1 and/or serum K19/K18 ratio may be helpful to discriminate between $\mathrm{HCC}$ and intrahepatic cholangiocarcinoma given that the latter displays stronger K19 expression. ${ }^{(94)}$

Numerous reports have assessed the potential usefulness of the above-mentioned tumor markers in liver disease. For CYFRA 21-1, the diagnostic benefit in nonmalignant liver diseases is likely small given that K19 is expressed only in cholangiocytes in unstressed livers, and even upon injury, hepatocellular K19 levels are rather low. ${ }^{(9)}$ Although CYFRA 21-1 has not been adequately assessed in cholestatic liver disorders, it has been studied in the context of other liver diseases. For example, patients with alcoholic hepatitis displayed increased CYFRA 21-1 levels, ${ }^{(95)}$ which meshes well with the associated strong ductular reaction. ${ }^{(96)}$ Unlike CYFRA 21-1, TPA and TPS are commonly elevated in patients with both malignant and nonmalignant liver diseases and therefore lack sufficient specificity for HCC

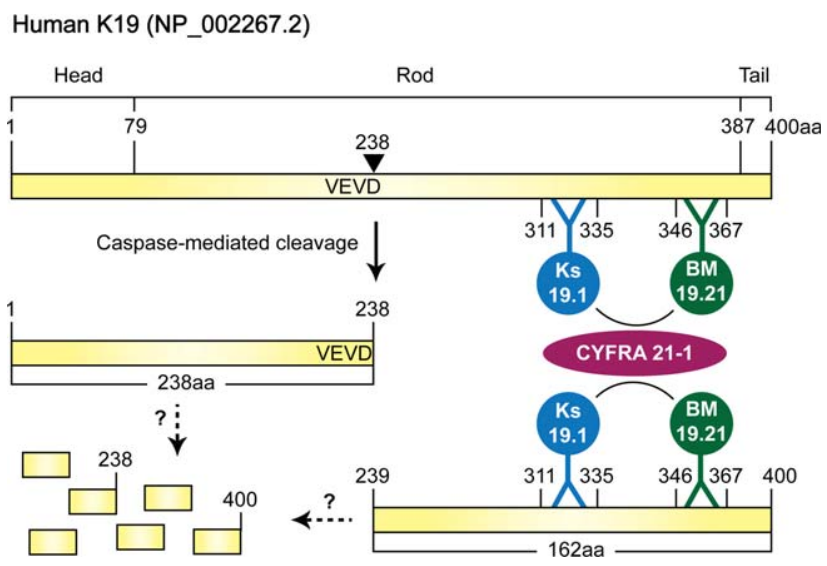

FIG. 4. K19 cleavage during apoptosis. Human K19 has one caspase cleavage site at $\mathrm{VEVD}^{238}$ that is conserved among other intermediate filaments. The CYFRA 21-1 assay (Cisbio Bioassays, Codolet, France) is performed using two monoclonal antibodies for K19: The capture antibody Ks 19.1 (recognizes 311335aa) and the detection antibody BM 19.21 (recognizes 346367aa). The CYFRA 21-1 assay does not discriminate between apoptotic and total cell death because both antibodies simply recognize the K19 rod domain. Abbreviation: aa, amino acids.

detection. ${ }^{(97)}$ On the other hand, increased TPS levels may predict early $\mathrm{HCC}$ recurrence after curative resection. ${ }^{(97)}$ In cirrhosis, TPA strongly correlates with (but might be more sensitive than) AST values. ${ }^{(98)}$ Moreover, TPA might discriminate between subjects without and with cirrhosis given that it correlates with hepatic vein pressure gradient, a central parameter of portal hypertension. ${ }^{(99)}$ TPS was found to be elevated in patients with multiple nonmalignant liver diseases and to correlate with AST levels and histological score of disease severity. ${ }^{(100)}$ Of note, TPS was elevated in one third of liver disease patients with normal liver enzyme values, suggesting that it might be more sensitive than AST. ${ }^{(100)}$ In alcoholic liver disease subjects, TPS was lower in those with less-severe steatosis/fibrosteatosis compared to those with life-threatening alcoholic hepatitis. ${ }^{(101)}$ TPS levels also correlated with the extent of Mallory-Denk bodies (K8/K18-containing inclusions characteristic of alcoholic liver disease/NASH) ${ }^{(9)}$ but the clinical significance of this finding remains unknown. ${ }^{(101)}$ In NAFLD, one study found TPS to be superior to ALT in discriminating NASH from simple steatosis. ${ }^{(102)}$ Despite these interesting findings, more work is needed on TPA/TPS to evaluate whether or not they offer an advantage to already established parameters. Given their biological similarity, it is tempting to speculate that TPS and M65 might be equally useful for subclassification of nonmalignant liver disorders. 


\section{Conclusion and Caveats of Measuring Keratin Fragments During Liver Injury}

For liver injury, the M30 ELISA is a biologically sound reflection of the extent of early-stage hepatocyte/ cholangiocyte apoptosis, though necrosis may accompany apoptosis. Moreover, intact keratins or non-caspase generated keratin fragments may be released during apoptosis. Notably, M30 does not measure late apoptosis stages that include generation of the second K18 caspase cleavage product, and, at least in cell culture systems, the M30 reactivity disappears in some apoptotic cells whereas reactivity of the antibody that recognizes the K18 second cut site persists. ${ }^{\left({ }^{33)}\right.}$ Also, an important unknown is the stability of various keratin species in serum in the context of different liver diseases. This caveat applies to all the currently used ELISAs that detect M30/M65/TPA/TPS/CYFRA 21-1.

With regard to the M65 ELISA, it is used to measure serum/plasma total or fragment K18 species using the monoclonal antibodies, M5 and M6, whose epitopes are located between K18 amino acids 300$380^{(90)}$ (Fig. 1). Hence, M65 detects not only nonapoptotic K18 fragments and intact K18, but also the 159aa apoptotic K18 fragment. This indicates that the M65 ELISA does not exclusively represent nonapoptotic K18, and that M65 may overlap with TPA and TPS depending on the biological and clinical contexts.

Another variable that is usually not accounted for in studies that measured keratin fragments is the presence of nonhepatic epithelial tissue injury or inflammation (gastrointestinal, lung, and kidney; tissues that express K8/K18/K19). Such extrahepatobiliary organ involvement could provide false-positive readings of K8/K18/ K19 fragments, given that these keratins and their fragments can also spill into the circulation.

Although numerous studies have measured keratin fragments as biomarkers of liver (Fig. 3 and Supporting Table 1) and other tissue injury, it is important to have a better appreciation of the species that are being measured. For example, it would be meaningful to compare the M30/M65 assays with (currently unavailable) ELISAs that would detect epitopes spanning the undigested K18 aspartates, 238 and 397. Also, there is no available ELISA that is directed to K18 Asp238, and such an ELISA, once established, is predicted to recognize both K18/K19 aspartates given their conserved proximal sequence. Mass spectrometry and other immunobiochemical tools may also help define the precise nature of the keratin species in sera from patients with different liver and other diseases that associate with release of K8/K18/K19 species. For example, it is possible that PTMs of circulating intact keratins or their fragments may provide an added dimension to use as biomarkers. ${ }^{(26)}$

In conclusion, the detection of circulating keratin species remains a useful adjunct for the assessment of liver injury. The abundance of keratins in liver tissue and normal physiologic presence in the cytoplasm, coupled with their relative stability, ${ }^{(9,33)}$ provide important support for their use as durable and sensitive liver injury biomarkers. Furthermore, the nature of keratin fragments (apoptotic vs. nonapoptotic) might provide insight regarding the cause(s) of liver injury. Better understanding of the mode of release and biochemical form of circulating keratins will likely enhance their diagnostic and potential prognostic utility.

\section{REFERENCES}

1) Ku NO, Zhou X, Toivola DM, Omary MB. The cytoskeleton of digestive epithelia in health and disease. Am J Physiol 1999; 277:G1108-G1137.

2) Fuchs E, Weber K. Intermediate filaments: structure, dynamics, function, and disease. Annu Rev Biochem 1994;63:345-382.

3) Omary MB, Coulombe PA, McLean WH. Intermediate filament proteins and their associated diseases. N Engl J Med 2004;351:2087-2100.

4) Burke B, Stewart CL. The nuclear lamins: flexibility in function. Nat Rev Mol Cell Biol 2013;14:13-24.

5) Coulombe PA, Omary MB. 'Hard' and 'soft' principles defining the structure, function and regulation of keratin intermediate filaments. Curr Opin Cell Biol 2002;14:110-122.

6) Moll R, Franke WW, Schiller DL, Geiger B, Krepler R. The catalog of human cytokeratins: patterns of expression in normal epithelia, tumors and cultured cells. Cell 1982;31:11-24.

7) Schweizer J, Bowden PE, Coulombe PA, Langbein L, Lane EB, Magin TM, et al. New consensus nomenclature for mammalian keratins. J Cell Biol 2006;174:169-174.

8) Herrmann H, Bar H, Kreplak L, Strelkov SV, Aebi U. Intermediate filaments: from cell architecture to nanomechanics. Nat Rev Mol Cell Biol 2007;8:562-573.

9) Omary MB, Ku NO, Strnad P, Hanada S. Toward unraveling the complexity of simple epithelial keratins in human disease. J Clin Invest 2009;119:1794-1805.

10) Luedde T, Kaplowitz N, Schwabe RF. Cell death and cell death responses in liver disease: mechanisms and clinical relevance. Gastroenterology 2014;147:765-783.e4.

11) Taylor RC, Cullen SP, Martin SJ. Apoptosis: controlled demolition at the cellular level. Nat Rev Mol Cell Biol 2008;9: 231-241. 
12) Akazawa Y, Gores GJ. Death receptor-mediated liver injury. Semin Liver Dis 2007;27:327-338.

13) Galle PR, Hofmann WJ, Walczak H, Schaller H, Otto G, Stremmel W, et al. Involvement of the CD95 (APO-1/Fas) receptor and ligand in liver damage. J Exp Med 1995;182: 1223-1230.

14) Fischer U, Janicke RU, Schulze-Osthoff K. Many cuts to ruin: a comprehensive update of caspase substrates. Cell Death Differ 2003;10:76-100

15) Adrain C, Duriez PJ, Brumatti G, Delivani P, Martin SJ. The cytotoxic lymphocyte protease, granzyme $\mathrm{B}$, targets the cytoskeleton and perturbs microtubule polymerization dynamics. J Biol Chem 2006;281:8118-8125.

16) Gerner C, Frohwein U, Gotzmann J, Bayer E, Gelbmann D, Bursch W, et al. The Fas-induced apoptosis analyzed by high throughput proteome analysis. J Biol Chem 2000;275:3901839026.

17) Rao L, Perez D, White E. Lamin proteolysis facilitates nuclear events during apoptosis. J Cell Biol 1996;135:14411455.

18) Caulin C, Salvesen GS, Oshima RG. Caspase cleavage of keratin 18 and reorganization of intermediate filaments during epithelial cell apoptosis. J Cell Biol 1997;138:1379-1394.

19) Ku NO, Liao J, Omary MB. Apoptosis generates stable fragments of human type I keratins. J Biol Chem 1997;272:3319733203.

20) Ku NO, Michie S, Oshima RG, Omary MB. Chronic hepatitis, hepatocyte fragility, and increased soluble phosphoglycokeratins in transgenic mice expressing a keratin 18 conserved arginine mutant. J Cell Biol 1995;131:1303-1314.

21) Loranger A, Duclos S, Grenier A, Price J, Wilson-Heiner M, Baribault H, Marceau N. Simple epithelium keratins are required for maintenance of hepatocyte integrity. Am J Pathol 1997;151:1673-1683.

22) Wagner OI, Rammensee S, Korde N, Wen $\mathrm{Q}_{2}$ Leterrier JF, Janmey PA. Softness, strength and self-repair in intermediate filament networks. Exp Cell Res 2007;313:2228-2235.

23) Kim S, Wong P, Coulombe PA. A keratin cytoskeletal protein regulates protein synthesis and epithelial cell growth. Nature 2006;441:362-365.

24) Tao GZ, Looi KS, Toivola DM, Strnad P, Zhou Q, Liao J, et al. Keratins modulate the shape and function of hepatocyte mitochondria: a mechanism for protection from apoptosis. J Cell Sci 2009;122:3851-3855.

25) Toivola DM, Boor P, Alam C, Strnad P. Keratins in health and disease. Curr Opin Cell Biol 2015;32:73-81.

26) Snider NT, Omary MB. Post-translational modifications of intermediate filament proteins: mechanisms and functions. Nat Rev Mol Cell Biol 2014;15:163-177.

27) Toivola DM, Ku NO, Resurreccion EZ, Nelson DR, Wright TL, Omary MB. Keratin 8 and 18 hyperphosphorylation is a marker of progression of human liver disease. Hepatology 2004;40:459-466.

28) Ku NO, Michie SA, Soetikno RM, Resurreccion EZ, Broome RL, Omary MB. Mutation of a major keratin phosphorylation site predisposes to hepatotoxic injury in transgenic mice. J Cell Biol 1998;143:2023-2032.

29) Ku NO, Omary MB. A disease- and phosphorylation-related nonmechanical function for keratin 8. J Cell Biol 2006;174: 115-125.

30) Leers MP, Kolgen W, Bjorklund V, Bergman T, Tribbick G, Persson B, et al. Immunocytochemical detection and mapping of a cytokeratin 18 neo- epitope exposed during early apoptosis. J Pathol 1999;187:567-572.
31) Ku NO, Omary MB. Effect of mutation and phosphorylation of type I keratins on their caspase-mediated degradation. J Biol Chem 2001;276:26792-26798.

32) Schutte B, Henfling M, Kolgen W, Bouman M, Meex S, Leers $\mathrm{MP}$, et al. Keratin 8/18 breakdown and reorganization during apoptosis. Exp Cell Res 2004;297:11-26.

33) Tao GZ, Li DH, Zhou Q, Toivola DM, Strnad P, Sandesara $\mathrm{N}$, et al. Monitoring of epithelial cell caspase activation via detection of durable keratin fragment formation. J Pathol 2008; 215:164-174

34) Weerasinghe SV, Ku NO, Altshuler PJ, Kwan R, Omary MB. Mutation of caspase-digestion sites in keratin 18 interferes with filament reorganization, and predisposes to hepatocyte necrosis and loss of membrane integrity. J Cell Sci 2014;127: 1464-1475.

35) Stegh AH, Herrmann H, Lampel S, Weisenberger D, Andrä $\mathrm{K}$, Seper M, et al. Identification of the cytolinker plectin as a major early in vivo substrate for caspase 8 during CD95- and tumor necrosis factor receptor-mediated apoptosis. Mol Cell Biol 2000;20:5665-5679.

36) Szeverenyi I, Cassidy AJ, Chung CW, Lee BT, Common JE, Ogg SC, et al. The Human Intermediate Filament Database: comprehensive information on a gene family involved in many human diseases. Hum Mutat 2008;29:351-360.

37) Omary MB. "IF-pathies": a broad spectrum of intermediate filament-associated diseases. J Clin Invest 2009;119:17561762.

38) Usachov V, Urban TJ, Fontana RJ, Gross A, Iyer S, Omary $\mathrm{MB}$, et al. Prevalence of genetic variants of keratins 8 and 18 in patients with drug-induced liver injury. BMC Med 2015;13: 196.

39) Ku NO, Gish R, Wright TL, Esquivel CO, Keeffe EB, Sibley $\mathrm{RK}$, et al. Keratin 8 mutations in patients with cryptogenic liver disease. N Engl J Med 2001;344:1580-1587.

40) Strnad P, Paschke S, Jang KH, Ku NO. Keratins: markers and modulators of liver disease. Curr Opin Gastroenterol 2012;28: 209-216.

41) Zhong B, Strnad P, Selmi C, Invernizzi P, Tao GZ, Caleffi A, et al. Keratin variants are over-represented in primary biliary cirrhosis and associate with disease severity. Hepatology 2009; 50:546-554.

42) Strnad P, Zhou Q, Hanada S, Lazzeroni LC, Zhong BH, So $\mathrm{P}$, et al. Keratin variants predispose to adverse outcomes from acute liver failure: race and ethnic associations. Gastroenterology 2010;139:828-835.

43) Ku NO, Soetikno RM, Omary MB. Keratin mutation in transgenic mice predisposes to Fas but not TNF-induced apoptosis and massive liver injury. Hepatology 2003;37:10061014.

44) Treiber M, Schulz HU, Landt O, Drenth JP, Castellani C, Real FX, et al. Keratin 8 sequence variants in patients with pancreatitis and pancreatic cancer. J Mol Med 2006;84:1015-1022.

45) Bravo AA, Sheth SG, Chopra S. Liver biopsy. N Engl J Med 2001;344:495-500.

46) Regev A, Berho M, Jeffers LJ, Milikowski C, Molina EG, Pyrsopoulos NT, et al. Sampling error and intraobserver variation in liver biopsy in patients with chronic $\mathrm{HCV}$ infection. Am J Gastroenterol 2002;97:2614-2618.

47) Guicciardi ME, Malhi H, Mott JL, Gores GJ. Apoptosis and necrosis in the liver. Compr Physiol 2013;3:977-1010.

48) Eguchi A, Wree A, Feldstein AE. Biomarkers of liver cell death. J Hepatol 2014;60:1063-1074.

49) Bantel H, Lugering A, Heidemann J, Volkmann X, Poremba C, Strassburg CP, et al. Detection of apoptotic caspase 
activation in sera from patients with chronic HCV infection is associated with fibrotic liver injury. HEPATOLOGY 2004;40:10781087.

50) Volkmann X, Anstaett M, Hadem J, Stiefel P, Bahr MJ, Lehner F, et al. Caspase activation is associated with spontaneous recovery from acute liver failure. Hepatology 2008;47: 1624-1633.

51) McFarlane M, Merrison W, Dinsdale D, Cohen GM. Active caspases and cleaved cytokeratins are sequestered into cytoplasmic inclusions in TRAIL-induced apoptosis. J Cell Biol 2000; 148:1239-1254.

52) Minciacchi VR, You S, Spinelli C, Morley S, Zandian M, Aspuria PJ, et al. Large oncosomes contain distinct protein cargo and represent a separate functional class of tumor-derived extracellular vesicles. Oncotarget 2015;6:11327-11341.

53) Harris AC, Ferrara JL, Braun TM, Holler E, Teshima T, Levine JE, et al. Plasma biomarkers of lower gastrointestinal and liver acute GVHD. Blood 2012;119:2960-2963.

54) Rutherford AE, Hynan LS, Borges CB, Forcione DG, Blackard JT, Lin W, et al. Serum apoptosis markers in acute liver failure: a pilot study. Clin Gastroenterol Hepatol 2007;5: 1477-1483.

55) Dechene A, Sowa JP, Gieseler RK, Jochum C, Bechmann LP, El Fouly A, et al. Acute liver failure is associated with elevated liver stiffness and hepatic stellate cell activation. Hepatology 2010;52:1008-1016.

56) Bantel H, Schulze-Osthoff K. Mechanisms of cell death in acute liver failure. Front Physiol 2012;3:79.

57) Bechmann LP, Jochum C, Kocabayoglu P, Sowa JP, Kassalik M, Gieseler RK, et al. Cytokeratin 18-based modification of the MELD score improves prediction of spontaneous survival after acute liver injury. J Hepatol 2010;53:639-647.

58) Rutherford A, King LY, Hynan LS, Vedvyas C, Lin W, Lee WM, et al. Development of an accurate index for predicting outcomes of patients with acute liver failure. Gastroenterology 2012;143:1237-1243.

59) Antoine DJ, Jenkins RE, Dear JW, Williams DP, McGill MR, Sharpe MR, et al. Molecular forms of HMGB1 and keratin-18 as mechanistic biomarkers for mode of cell death and prognosis during clinical acetaminophen hepatotoxicity. J Hepatol 2012; 56:1070-109.

60) Possamai LA, McPhail MJ, Quaglia A, Zingarelli V, Abeles $\mathrm{RD}$, Tidswell $\mathrm{R}$, et al. Character and temporal evolution of apoptosis in acetaminophen-induced acute liver failure. Crit Care Med 2013;41:2543-2550.

61) Craig DG, Lee P, Pryde EA, Masterton GS, Hayes PC, Simpson KJ. Circulating apoptotic and necrotic cell death markers in patients with acute liver injury. Liver Int 2011;31: 1127-1136.

62) Mehal W, Imaeda A. Cell death and fibrogenesis. Semin Liver Dis 2010;30:226-231.

63) Papatheodoridis GV, Hadziyannis E, Tsochatzis E, Chrysanthos N, Georgiou A, Kafiri G, et al. Serum apoptotic caspase activity as a marker of severity in $\mathrm{HBeAg}-$ negative chronic hepatitis B virus infection. Gut 2008;57: 500-506.

64) Bae CB, Kim SS, Ahn SJ, Cho HJ, Kim SR, Park SY, et al. Caspase-cleaved fragments of cytokeratin-18 as a marker of inflammatory activity in chronic hepatitis B virus infection. J Clin Virol 2013;58:641-646.

65) Parfieniuk-Kowerda A, Lapinski TW, Rogalska-Plonska M, Swiderska M, Panasiuk A, Jaroszewicz J, Flisiak R. Serum cytochrome $\mathrm{c}$ and $\mathrm{m} 30$-neoepitope of cytokeratin-18 in chronic hepatitis C. Liver Int 2014;34:544-550.
66) Farnik H, Lange CM, Hofmann WP, Berger A, Allwinn R, Welker MW, et al. Nucleos(t)ide analogue treatment reduces apoptotic activity in patients with chronic hepatitis B. J Clin Virol 2011;52:204-209.

67) Volkmann X, Cornberg M, Wedemeyer H, Lehner F, Manns $\mathrm{MP}$, Schulze-Osthoff $\mathrm{K}$, Bantel $\mathrm{H}$. Caspase activation is required for antiviral treatment response in chronic hepatitis $\mathrm{C}$ virus infection. Hepatology 2006;43:1311-1316.

68) Kronenberger B, Wagner M, Herrmann E, Mihm U, Piiper A, Sarrazin C, Zeuzem S. Apoptotic cytokeratin 18 neoepitopes in serum of patients with chronic hepatitis C. J Viral Hepat 2005; $12: 307-314$.

69) Joka D, Wahl K, Moeller S, Schlue J, Vaske B, Bahr MJ, et al. Prospective biopsy-controlled evaluation of cell death biomarkers for prediction of liver fibrosis and nonalcoholic steatohepatitis. HePatology 2012;55:455-464.

70) Rinella ME. Nonalcoholic fatty liver disease: a systematic review. JAMA 2015;313:2263-2273.

71) Browning JD, Szczepaniak LS, Dobbins R, Nuremberg P, Horton JD, Cohen JC, et al. Prevalence of hepatic steatosis in an urban population in the United States: impact of ethnicity. Hepatology 2004;40:1387-1395.

72) Fracanzani AL, Valenti L, Bugianesi E, Andreoletti M, Colli A, Vanni E, et al. Risk of severe liver disease in nonalcoholic fatty liver disease with normal aminotransferase levels: a role for insulin resistance and diabetes. Hepatology 2008;48:792-798.

73) Mofrad P, Contos MJ, Haque M, Sargeant C, Fisher RA, Luketic VA, et al. Clinical and histologic spectrum of nonalcoholic fatty liver disease associated with normal ALT values. Hepatology 2003;37:1286-1292.

74) Wong VW, Wong GL, Choi PC, Chan AW, Li MK, Chan $\mathrm{HY}$, et al. Disease progression of non-alcoholic fatty liver disease: a prospective study with paired liver biopsies at 3 years. Gut 2010;59:969-974.

75) Castera L. Noninvasive evaluation of nonalcoholic fatty liver disease. Semin Liver Dis 2015;35:291-303.

76) Wieckowska A, Zein NN, Yerian LM, Lopez AR, McCullough AJ, Feldstein AE. In vivo assessment of liver cell apoptosis as a novel biomarker of disease severity in nonalcoholic fatty liver disease. HePATOLOGY 2006;44:27-33.

77) Diab DL, Yerian L, Schauer P, Kashyap SR, Lopez R, Hazen SL, Feldstein AE. Cytokeratin 18 fragment levels as a noninvasive biomarker for nonalcoholic steatohepatitis in bariatric surgery patients. Clin Gastroenterol Hepatol 2008;6:1249-1254.

78) Cusi K, Chang Z, Harrison S, Lomonaco R, Bril F, Orsak B, et al. Limited value of plasma cytokeratin-18 as a biomarker for NASH and fibrosis in patients with non-alcoholic fatty liver disease. J Hepatol 2014;60:167-174.

79) Shen J, Chan HL, Wong GL, Choi PC, Chan AW, Chan $\mathrm{HY}$, et al. Non-invasive diagnosis of non-alcoholic steatohepatitis by combined serum biomarkers. J Hepatol 2012;56:13631370

80) Tamimi TI, Elgouhari HM, Alkhouri N, Yerian LM, Berk MP, Lopez R, et al. An apoptosis panel for nonalcoholic steatohepatitis diagnosis. J Hepatol 2011;54:1224-1229.

81) Tsutsui M, Tanaka N, Kawakubo M, Sheena Y, Horiuchi A, Komatsu M, et al. Serum fragmented cytokeratin 18 levels reflect the histologic activity score of nonalcoholic fatty liver disease more accurately than serum alanine aminotransferase levels. J Clin Gastroenterol 2010;44:440-447.

82) Kleiner DE, Brunt EM, Van Natta M, Behling C, Contos MJ, Cummings OW, et al. Design and validation of a histological scoring system for nonalcoholic fatty liver disease. HePATOLOGY 2005;41:1313-1321. 
83) Vuppalanchi R, Jain AK, Deppe R, Yates K, Comerford M, Masuoka HC, et al. Relationship between changes in serum levels of keratin 18 and changes in liver histology in children and adults with nonalcoholic fatty liver disease. Clin Gastroenterol Hepatol 2014;12:2121-2130.e1-2.

84) Anty R, Iannelli A, Patouraux S, Bonnafous S, Lavallard VJ, Senni-Buratti M, et al. A new composite model including metabolic syndrome, alanine aminotransferase and cytokeratin-18 for the diagnosis of non-alcoholic steatohepatitis in morbidly obese patients. Aliment Pharmacol Ther 2010;32:1315-1322.

85) Younossi ZM, Jarrar M, Nugent C, Randhawa M, Afendy M, Stepanova M, et al. A novel diagnostic biomarker panel for obesity-related nonalcoholic steatohepatitis (NASH). Obes Surg 2008;18:1430-1437.

86) Shen J, Chan HL, Wong GL, Chan AW, Choi PC, Chan $\mathrm{HY}$, et al. Assessment of non-alcoholic fatty liver disease using serum total cell death and apoptosis markers. Aliment Pharmacol Ther 2012;36:1057-1066.

87) Adams LA, Crawford DH, Stuart K, House MJ, St Pierre TG, Webb M, et al. The impact of phlebotomy in nonalcoholic fatty liver disease: a prospective, randomized, controlled trial. HePATOLOGY 2015;61:1555-1564.

88) Sawant SS, Zingde SM, Vaidya MM. Cytokeratin fragments in the serum: their utility for the management of oral cancer. Oral Oncol 2008;44:722-732.

89) Rydlander L, Ziegler E, Bergman T, Schöberl E, Steiner G, Bergman AC, et al. Molecular characterization of a tissuepolypeptide-specific-antigen epitope and its relationship to human cytokeratin 18. Eur J Biochem 1996;241:309-314.

90) Kramer G, Erdal H, Mertens HJ, Nap M, Mauermann J, Steiner G, et al. Differentiation between cell death modes using measurements of different soluble forms of extracellular cytokeratin 18. Cancer Res 2004;64:1751-1756.

91) Ding SJ, Li Y, Tan YX, Jiang MR, Tian B, Liu YK, et al. From proteomic analysis to clinical significance: overexpression of cytokeratin 19 correlates with hepatocellular carcinoma metastasis. Mol Cell Proteomics 2004;3:73-81.

92) Toh HC, Chen PJ, Carr BI, Knox JJ, Gill S, Ansell P, et al. Phase 2 trial of linifanib (ABT-869) in patients with unresectable or metastatic hepatocellular carcinoma. Cancer 2013;119: 380-387.

93) Govaere O, Komuta M, Berkers J, Spee B, Janssen C, de Luca F, et al. Keratin 19: a key role player in the invasion of human hepatocellular carcinomas. Gut 2014;63:674-685.
94) Uenishi T, Kubo S, Yamamoto T, Shuto T, Ogawa M, Tanaka $\mathrm{H}$, et al. Cytokeratin 19 expression in hepatocellular carcinoma predicts early postoperative recurrence. Cancer Sci 2003;94:851857.

95) Gonzalez-Quintela A, Garcia J, Campos J, Perez LF, Alende MR, Otero E, et al. Serum cytokeratins in alcoholic liver disease: contrasting levels of cytokeratin-18 and cytokeratin-19. Alcohol 2006;38:45-49.

96) Sancho-Bru P, Altamirano J, Rodrigo-Torres D, Coll M, Millán C, José Lozano J, et al. Liver progenitor cell markers correlate with liver damage and predict short-term mortality in patients with alcoholic hepatitis. Hepatology 2012;55:19311941.

97) Yao WJ, Wang ST, Chow NH, Chang TT, Lin PW, Tu DG. Serum tissue polypeptide specific antigen as a noninvasive prognostic indicator for early recurrence of hepatocellular carcinoma after curative resection. Cancer 2002;95:112-118.

98) Collazos J, Genolla J, Ruibal A. A clinical and laboratory evaluation of the behavior of tissue polypeptide antigen in liver cirrhosis. Digestion 1992;53:157-161.

99) Puoti C, Bellis L, Guarisco R, Costanza OM, Felici R, Spilabotti L, et al. Quantitation of tissue polypeptide antigen (TPA) in hepatic and systemic circulation in patients with chronic liver diseases. J Gastroenterol Hepatol 2009;24:18471851.

100) Gonzalez-Quintela A, Mallo N, Mella C, Campos J, Perez LF, Lopez-Rodriguez R, et al. Serum levels of cytokeratin-18 (tissue polypeptide-specific antigen) in liver diseases. Liver Int 2006;26:1217-1224.

101) Gonzalez-Quintela A, Mella C, Perez LF, Abdulkader I, Caparrini AM, Lojo S. Increased serum tissue polypeptide specific antigen (TPS) in alcoholics: a possible marker of alcoholic hepatitis. Alcohol Clin Exp Res 2000;24:1222-1226.

102) Tarantino G, Conca P, Coppola A, Vecchione R, Di Minno G. Serum concentrations of the tissue polypeptide specific antigen in patients suffering from non-alcoholic steatohepatitis. Eur J Clin Invest 2007;37:48-53.

\section{Supporting Information}

Additional Supporting Information may be found at onlinelibrary.wiley.com/doi/10.1002/hep.28493/suppinfo. 